\title{
Pto- and Prf-Mediated Recognition of AvrPto and AvrPtoB Restricts the Ability of Diverse Pseudomonas syringae Pathovars to Infect Tomato
}

\author{
Nai-Chun Lin ${ }^{1,2}$ and Gregory B. Martin ${ }^{1,3}$ \\ ${ }^{1}$ Boyce Thompson Institute for Plant Research, Tower Rd., Ithaca, NY 14853-1801, U.S.A.; ${ }^{2}$ Department of Agricultural \\ Chemistry, National Taiwan University, Taipei 10617, Taiwan, Republic of China; ${ }^{3}$ Department of Plant Pathology, \\ Cornell University, Ithaca, NY 14853-4203, U.S.A.
}

Submitted 15 December 2006. Accepted 19 February 2007.

The molecular basis underlying the ability of pathogens to infect certain plant species and not others is largely unknown. Pseudomonas syringae is a useful model species for investigating this phenomenon because it comprises more than 50 pathovars which have narrow host range specificities. Tomato (Solanum lycopersicum) is a host for $P$. syringae pv. tomato, the causative agent of bacterial speck disease, but is considered a nonhost for other $P$. syringae pathovars. Host resistance in tomato to bacterial speck disease is conferred by the Pto protein kinase which acts in concert with the Prf nucleotide-binding lucine-rich repeat protein to recognize $P$. syringae pv. tomato strains expressing the type III effectors AvrPto or AvrPtoB (HopAB2). The Pto and Prf genes were isolated from the wild tomato species $S$. pimpinellifolium and functional alleles of both of these genes now are known to exist in many species of tomato and in other Solanaceous species. Here, we extend earlier reports that avrPto and avrPtoB genes are widely distributed among pathovars of $P$. syringae which are considered nonhost pathogens of tomato. This observation prompted us to examine the possibility that recognition of these type III effectors by Pto or Prf might contribute to the inability of many $P$. syringae pathovars to infect tomato species. We show that 10 strains from presumed nonhost $P$. syringae pathovars are able to grow and cause pathovar-unique disease symptoms in tomato leaves lacking Pto or Prf, although they did not reach the population levels or cause symptoms as severe as a control $P$. syringae pv. tomato strain. Seven of these strains were found to express avrPto or avrPtoB. The AvrPto- and AvrPtoBexpressing strains elicited disease resistance on tomato leaves expressing Pto and Prf. Thus, a gene-for-gene recognition event may contribute to host range restriction of many $P$. syringae pathovars on tomato species. Furthermore, we conclude that the diverse disease symptoms caused by different Pseudomonas pathogens on their normal plant hosts are due largely to the array of virulence factors expressed by each pathovar and not to specific molecular or morphological attributes of the plant host.

Corresponding author: G. B. Martin; Telephone: 607-254-1208; Fax: 607255-6695; E-mail: gbm7@ cornell.edu

* The $e$-Xtra logo stands for "electronic extra" and indicates additional material is available online. Three supplemental tables and four supplemental figures are published online.
Additional keywords: nonhost resistance, $R$ genes.

The reasons why specific pathogens infect certain plant species but are unable to infect others are mostly unknown (Keen 1988; Mysore and Ryu 2004; Thordal-Christensen 2003). In some cases, host range restriction appears to be due to the absence of a specific virulence factor in the pathogen that is required for colonization and growth in tissues of a certain species. One example of this scenario is the recent report that the HsvB type III effector protein is required for the ability of two pathovars of Pantoea agglomerans to grow on beet (Nissan et al. 2006). Other type III effectors also exhibit this ability to broaden host range (Chakrabarty and Gabriel 1997; Swarup et al. 1991). Alternatively, and not in a mutually exclusive manner, host range could be restricted by expression in the pathogen of a component that is recognized by the defense system of a nonhost plant species. A seminal observation supporting this possibility was the identification of three type III effector genes in the tomato pathogen Pseudomonas syringae pv. tomato which, when introduced into the soybean pathogen $P$. syringae pv. glycinea, caused a hypersensitive response (HR) in specific soybean cultivars (Kobayashi et al. 1989). Collectively, the three $P$. syringae pv. tomato genes accounted for all the HRs observed on different soybean cultivars. Therefore, this observation raised the possibility that the nonhost resistance of soybean to $P$. syringae pv. tomato might be due to recognition of one or more of these three type III effectors by widely conserved resistance $(R)$ genes present in different soybean cultivars.

A recent review has proposed classifying nonhost resistance into two types (Mysore and Ryu 2004). In type I nonhost resistance, no symptoms of pathogen attack are observed because the bacterium, fungus, or oomycete is unable to counter preformed defenses such as the host cell wall and antimicrobial compounds, or early inducible defenses such as cell wall thickening and phytoalexins. In contrast, the more widely studied type II nonhost resistance, which also occurs in response to various bacterial, fungal, and oomycete pathogens, is associated with the development of rapid localized cell death (the HR) at the site of attempted attack. Consistent with the interpretation from the soybean HR work described above (Kobayashi et al. 1989), it has been proposed that type II nonhost resistance shares some mechanistic similarities to host resistance mediated by plant $R$ genes (Abramovitch et al. 2006; Mysore and Ryu 2004). 
Although no direct molecular evidence for a role of $R$ genes in type II nonhost resistance has been reported, identification of NHO1 in Arabidopsis thaliana and SGT1 in Nicotiana benthamiana provides strong evidence that nonhost and host resistance share similar mechanisms ( $\mathrm{Lu}$ et al. 2001; Peart et al. 2002). NHO1, which encodes a glycerol kinase, originally was identified as a key component for type I nonhost resistance to P. syringae pv. phaseolicola NPS3121 (Lu et al. 2001). It also was found to be required for resistance in Arabidopsis, mediated by the $R$ genes $R P S 2, R P S 4, R P S 5$, and RPM1. Similarly, the ubiquitin ligase-associated protein SGT1 is required for $\mathrm{N}-$, $\mathrm{Rx}^{-}$, and Pto-mediated resistance and also for type II nonhost resistance of $N$. benthamiana against the Brassicaceae pathogen $P$. syringae pv. maculicola and pepper pathogen Xanthomonas axonopodis pv. vesicatoria (Peart et al. 2002).

Additional genetic evidence indicates that $R$ gene-mediated recognition might be involved in nonhost resistance. For example, avrPpiA1, a type III effector from the pea pathogen $P$. syringae pv. pisi recognized by $R P M 1$ in pea, also elicits nonhost resistance in interactions with functional RPMI homologs in Arabidopsis and bean (Dangl et al. 1992). Similarly, the region of maize chromosome 6 carrying the Rxol/Rbal locus was found to mediate an HR to both the host pathogen Burkholderia andropogonis and the nonhost pathogen X. oryzae pv. oryzicola, although it is unknown whether this is due to the action of the Rxol/Rbal $R$ genes (Zhao et al. 2004). The host range of a plant pathogen probably is determined in part by the stability of nonhost resistance directed against it. Therefore, it is likely that, if $\mathrm{R}$ proteins contribute significantly to nonhost resistance, they are targeted against widely distributed, conserved pathogen effectors or that $R$ genes present in a given plant species allow recognition of multiple diverse effectors.

The species $P$. syringae is an excellent model system for investigating the molecular basis of bacterial pathogenesis and both host and nonhost resistance (Buell et al. 2003; Lindeberg et al. 2006; Preston 2000). Over 50 pathovars of $P$. syringae have been defined based on pathogenicity tests or on the plant host from which they were isolated and are thought to infect (Hirano and Upper 2000; Rudolph 1995; Sarkar and Guttman 2004). Thus, for example, $P$. syringae pv. tomato is a common pathogen of tomato but is considered a nonhost pathogen of bean, whereas the reverse is true for $P$. syringae pv. phaseolicola. Recently, the genomes have been sequenced of representative strains of both $P$. syringae pv. tomato and $P$. syringae pv. phaseolicola, and these pathogens have been shown to express approximately 30 and 20 confirmed type III effectors, respectively (Buell et al. 2003; Joardar et al. 2005; Lindeberg et al. 2006). Because type III effectors play a key role in bacterial virulence, it seems likely that they frequently make a fundamental contribution to host range specificity. The discovery that $P$. syringae pathovars express such a large number of type III effectors, combined with their host range specificity and experimental tractability, provides an ideal opportunity to use these organisms to investigate the molecular basis of nonhost resistance.

In tomato (Solanum lycopersicum), host resistance to $P$. syringae pv. tomato, the causative agent of bacterial speck disease, occurs upon recognition of the type III effectors AvrPto or AvrPtoB (hopAB2) by the $\mathrm{R}$ protein Pto, a serine/threonine protein kinase (Pedley and Martin 2003). Pto, which was isolated from the wild species $S$. pimpinellifolium, acts in concert with the nucleotide-binding lucine-rich repeat protein Prf to activate a variety of defense responses, including the HR (Mucyn et al. 2006; Salmeron et al. 1996). Functional Pto genes recently were reported to occur in approximately $35 \%$ of a subset of accessions of tomato wild species, and Pto-like genes also exist in other Solanaceous species (He et al. 2004;
Riely and Martin 2001; Rose et al. 2005; Thilmony et al. 1995; Vleeshouwers et al. 2001). Interestingly, although there are more than 50 classes of type III effectors in Pseudomonas spp., tomato is known to target only two of them, AvrPto and AvrPtoB, for activation of resistance (via Pto/Prf) (Lin and Martin 2005; Pedley and Martin 2003). AvrPto and AvrPtoB interfere with basal defenses in Arabidopsis and promote bacterial growth and ethylene-dependent disease-associated cell death in tomato plants lacking Pto or Prf (Cohn and Martin 2005; He et al. 2006). The apparent broad occurrence of avrPto and avrPtoB (hopAB)-like genes in diverse Pseudomonas spp. suggests that their virulence activities contribute to bacterial fitness in nature (Jackson et al. 2002; Lin et al. 2006; Sarkar et al. 2006).

The wide distribution of avrPto- and avrPtoB-related sequences among Pseudomonas pathovars and similar conservation of Pto and Prf genes in wild tomato species raises the possibility that a recognition event involving these genes might play a role in nonhost resistance of tomato species to $P$. syringae pathovars. Here, we show that Pto- or Prf-expressing tomato lines mediate a type II-like (HR) nonhost resistance to diverse $P$. syringae pathovars which express AvrPto or AvrPtoB homologs. Interestingly, tomato leaves lacking a functional Pto/Prf pathway did not display a nonhost HR and, in fact, $P$. syringae pathovars were able to infect these plants and cause a variety of pathovardistinct disease symptoms. Although populations of these $P$. syringae pathovars in leaves increased substantially during the infection period, they did not reach the high level of a control $P$. syringae pv. tomato strain. These observations suggest that the inability of many Pseudomonas pathovars to infect tomato species in the field is due to both a lack of certain tomato-specific type III effectors and, in many wild species of tomato, the presence of the Pto/Prf recognition system.

\section{RESULTS}

\section{AvrPto and AvrPtoB homologs are present and expressed in many $P$. syringae pathovars.}

We first examined whether avrPto- or $a v r P t o B$-like sequences were present in 10 isolates of diverse $P$. syringae pathovars representing various clades of this species (Table 1) (Sarkar and Guttman 2004). We detected avrPto-like sequences in $P$. syringae pvs. lachrymans, mori, phaseolicola, and syringae (Table 1; Supplementary Figure S1). AvrPtoB-like sequences were observed in eight of the isolates (but note that, in $P$. syringae pv. maculicola ES4326, these are C-terminal truncated forms of AvrPtoB, termed HopPmaL and HolPmaN) (Guttman et al. 2002). Two of the 10 isolates we examined, $P$. syringae pv. coronafaciens B142 and $P$. syringae pv. syringae 61 , did not contain either avrPto- or avrPtoB-like sequences (Table 1). We previously reported that the $P$. syringae pv. tomato T1 genome has an avrPtoB-related gene for which an mRNA transcript, but no protein, is detectable, leading to a compatible interaction with tomato lines expressing Pto/Prf (Lin et al. 2006). Therefore, we investigated by RNA and protein gel blot analyses whether Pseudomonas strains carrying avrPto- or avrPtoB-like sequences actually express these genes. Transcripts for $a v r P t o$ were detected in all of the strains expected except for $P$. syringae pv. phaseolicola NPS3121, whereas avrPtoBrelated transcripts were detected in all the strains expected except $P$. syringae pv. glycinea $\mathrm{F} 117, P$. syringae pv. mori, and $P$. syringae pv. phaseolicola NPS3121 (Table 1 and data not shown). However, these negative results likely are due to low abundance of the transcripts or lack of homology with our probe because AvrPto and AvrPtoB proteins were detected in all strains carrying avrPto- or avrPtoB-like sequences (Table 1 and Supplementary Figure S2). These data confirm and extend 
earlier observations showing that the avrPto- and avrPtoBrelated genes are present and expressed in many $P$. syringae pathovars which are not known to infect tomato (Lindeberg et al. 2006; Sarkar et al. 2006).

Elicitation of the HR by diverse $P$. syringae pathovars requires a functional Pto/Prf pathway in tomato plants.

$P$. syringae pathovars other than $P$. syringae pv. tomato (and, to a much lesser extent, $P$. syringae pv. syringae) (Jones 1991) are considered to be nonhost pathogens of tomato. Therefore, we investigated whether they would elicit a type II-like nonhost
HR on tomato plants. Electrolyte leakage from leaves often is used as an indicator of membrane damage that is associated with the HR (Goodman and Novacky 1994). Therefore, we infiltrated leaves of Rio Grande-PtoR (Pto/Pto, Prf/Prf) with a high titer (2 $\left.\times 10^{7} \mathrm{CFU} / \mathrm{ml}\right)$ of each strain, placed the disks in water, and at the timepoints shown, measured the conductivity (Fig. 1, Supplementary Table S1). We observed a relative conductivity of approximately 30 microSiemens $(\mu \mathrm{S})$ or more within $6 \mathrm{~h}$ in response to five of the seven strains expressing avrPto or avrPtoB (P. syringae pvs. angulata 9, lachrymans 3, mori, phaseolicola 3121, and tabaci 11528). Infiltration of $P$. syringae pvs.

Table 1. Characteristics of Pseudomonas isolates used in this study ${ }^{\mathrm{x}}$

\begin{tabular}{|c|c|c|c|c|c|c|c|}
\hline \multirow[b]{2}{*}{ Pseudomonas syringae isolate $^{\mathrm{y}}$} & \multirow[b]{2}{*}{ Host } & \multicolumn{2}{|c|}{ DNA } & \multicolumn{2}{|c|}{ RNA } & \multicolumn{2}{|c|}{ Protein } \\
\hline & & avrPto & avrPtoB & avrPto & avrPtoB & AvrPto & AvrPtoB \\
\hline angulata (Pan) Pan9 & Tobacco & - & + & ND & + & ND & + \\
\hline coronafaciens (Pco) B142 & Oat & - & - & - & - & - & - \\
\hline glycinea $(P g y)$ F117 & Soybean & - & + & ND & - & ND & + \\
\hline lachrymans (Pla) Pla3 & Cucurbit & + & + & + & + & + & + \\
\hline mori (Pmo) PDDCC4331 & Mulberry & + & + & + & - & + & + \\
\hline maculicola (Pma) ES4326 & Crucifers & - & $* \mathrm{z}$ & ND & $* \mathrm{z}$ & ND & $* \mathrm{z}$ \\
\hline phaseolicola (Pph) NPS3121 & Bean & + & + & - & - & + & + \\
\hline syringae (Psy) 61 & Lilac, bean & - & - & - & - & - & - \\
\hline syringae (Psy) B728a & Lilac, bean & + & + & + & + & + & + \\
\hline tabaci (Pta) 11528 & Tobacco & - & + & ND & + & ND & + \\
\hline tomato DC3000 & Tomato & + & + & + & + & + & + \\
\hline
\end{tabular}

${ }^{\mathrm{x}}$ Symbols: $-=$ no detectable fragments, $+=$ fragments detected using avrPto or avrPtoB as a probe in DNA or RNA gel blot assays or protein species detected using anti-AvrPto or anti-AvrPtoB antibodies, and $\mathrm{ND}=$ not done.

${ }^{y}$ Proposed abbreviations are shown in parentheses (Sarkar et al. 2006; Vivian and Mansfield 1993).

${ }^{\mathrm{z}}$ hopPmaL and holPmaN, C-terminus truncated forms of AvrPtoB (Guttman et al. 2002).

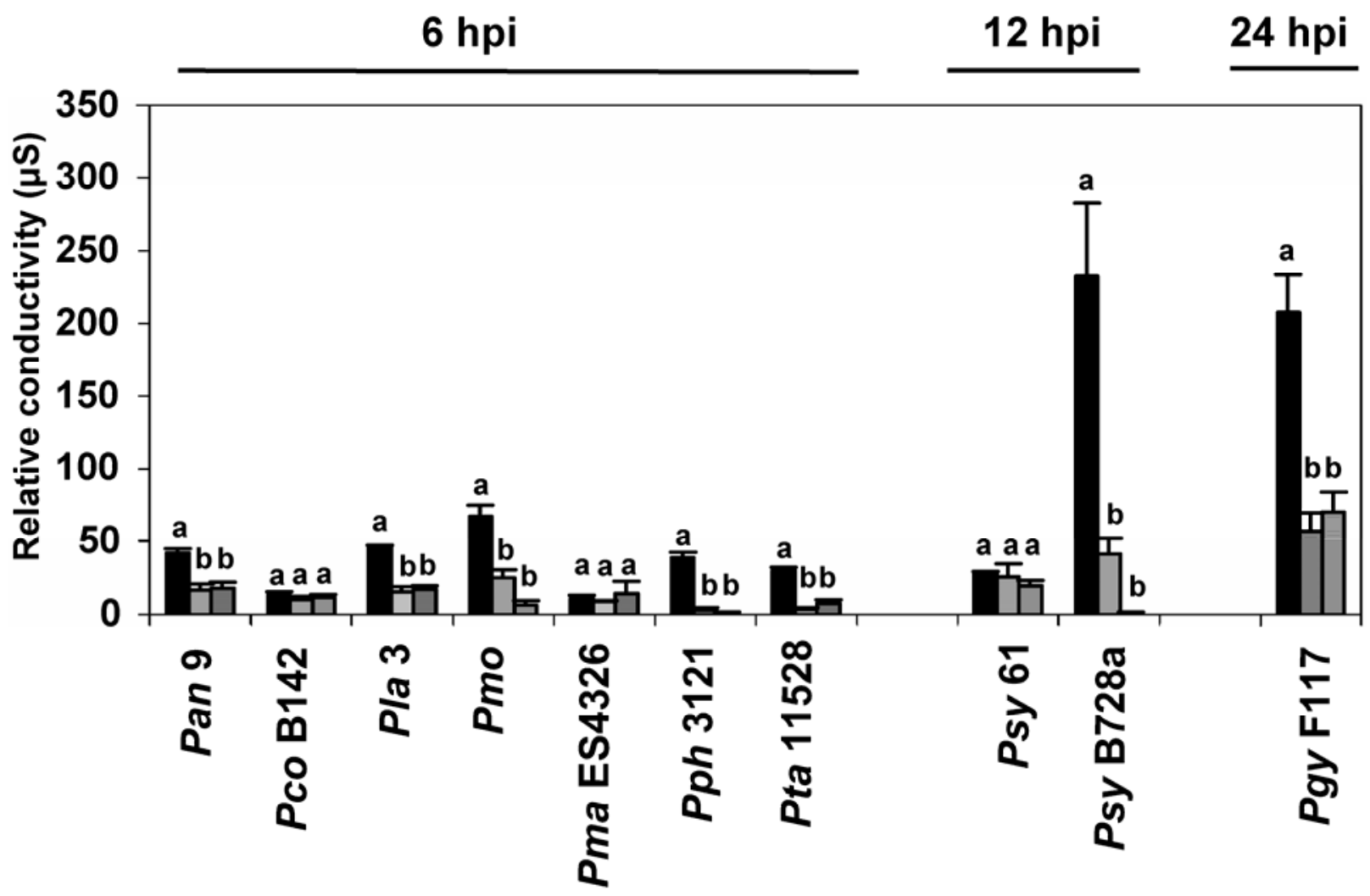

Fig. 1. Ion leakage caused by infiltration of various Pseudomonas syringae pathovars into tomato leaves. Degree of ion leakage from leaf areas of RG-PtoR (black), RG-pto11 (hatched), or RG-prf3 (gray) after infiltration with the P. syringae strains indicated at $2 \times 10^{7} \mathrm{CFU} / \mathrm{ml}$. Ion leakage is shown as relative conductivity (in microSiemens; $\mu \mathrm{S}$ ). Timepoints in hours postinfiltration (hpi) are shown at which leaf tissues showed the greatest differential response between RG-PtoR, RG-pto11, and RG-prf3 after infiltration with the indicated $P$. syringae isolate. Note that, at later timepoints, disease-associated cell death was observed with all $P$. syringae isolates. Bars indicate standard errors. Experiments presented in this figure were performed twice with similar results. The data from the two experiments were treated as replicates and were analyzed using Duncan's multiple range test. Means with the same letter assigned for each pathovar are not different at a significance level of 5\%. 
coronafaciens B142, maculicola ES4326, and syringae 61, which lack avrPto or avrPtoB homologs, resulted in lower conductivity at this timepoint (approximately $10 \mu \mathrm{S}$ ), although $P$. syringae pv. syringae 61 developed cell death (with approximately $30 \mu \mathrm{S}$ of conductivity) at $12 \mathrm{~h}$ postinfiltration. The two other isolates expressing avrPto or avrPtoB, P. syringae pv. syringae $\mathrm{B} 728 \mathrm{a}$ and $P$. syringae pv. glycinea $\mathrm{F} 117$, caused extensive cell death in RG-PtoR leaves at 12 and $24 \mathrm{~h}$ postinfiltration which was associated with high conductivity levels (approximately $200 \mu \mathrm{S}$ ). We previously have reported that infiltration of Rio Grande-PtoR leaves with $P$. syringae pv. tomato strains expressing AvrPto or AvrPtoB causes much greater cell death and high conductivity levels compared with an isogenic strain lacking these effectors (Lin and Martin 2005). Therefore, these data suggested that the conductivity levels above approximately 30 $\mu \mathrm{S}$ were due to early host cell death associated with the HR and not due to disease (this is further supported below). In summary, all $P$. syringae pv. tomato strains that contained AvrPto or AvrPtoB homologs caused enhanced ion leakage from RG-PtoR leaves, whereas the strains lacking these effectors did not.

To test whether these early cell death responses were mediated in part by the Pto/Prf pathway, we examined the effect of these 10 Pseudomonas strains on two tomato lines with mutations disrupting Pto or Prf (RG-pto11 carries a point mutation in Pto and RG-prf3 carries a deletion in Prf) (Salmeron et al. 1994). Interestingly, whether they expressed avrPto or avrPtoB homologs or not, none of these 10 strains caused enhanced ion leakage when infiltrated into RG-pto11 or RG-prf3 leaves at the timepoints where we previously saw ion leakage from leaves of RG-PtoR (Fig. 1; at later timepoints, all leaves developed disease symptoms and showed enhanced ion leakage). Notably, statistically significantly lower conductivity levels were observed in RG-pto11 and RG-prf3 compared with RGPtoR for those strains expressing avrPto or avrPtoB homologs (Fig. 1). In addition, there was no statistically significant difference among any of the three tomato lines in their response to $P$. syringae pvs. coronafaciens B142, syringae 61, or macu- licola ES4326, which lack both avrPto and avrPtoB (Fig. 1; note that $P$. syringae pv. maculicola ES4326 carries truncated forms of $a v r P t o B$ ). These observations indicated that a Pto/Prfmediated gene-for-gene interaction is responsible for the rapid cell death (HR) caused by avrPto- or avrPtoB-expressing $P$. syringae pathovars in RG-PtoR.

\section{Diverse $P$. syringae pathovars can infect tomato leaves, and Pto/Prf inhibit disease symptom formation.}

Because these $P$. syringae pathovars are considered nonhost pathogens of tomato and we had used a high titer of bacteria in our earlier experiments, we were surprised at the lack of a nonhost-like HR in RG-pto11 and RG-prf3 (Goodman and Novacky 1994). To further investigate the response of tomato lines with and without Pto or Prf to these P. syringae pathovars, we vacuum infiltrated tomato leaves with a low titer $\left(2 \times 10^{4}\right.$ $\mathrm{CFU} / \mathrm{ml}$ ) of the different strains and monitored the progress of disease development. Unexpectedly, disease symptoms developed on leaves of tomato lines RG-prf3 and RG-pto11 4 days after inoculation with each of the 10 strains (Fig. 2; Table 2; Supplementary Figure S3; data not shown for all RG-pto11 interactions). No symptoms occurred on leaves of RG-PtoR inoculated with the avrPto- or avrPtoB-expressing strains (Table 2). P. syringae pvs. coronafaciens B142, maculicola ES4326, and syringae 61, which did not trigger an HR on RG-PtoR, caused disease symptoms on leaves of RG-PtoR as well as on RG-pto11 and RG-prf3 (Table 2). It is possible that vacuum infiltration of leaves bypasses some plant defenses against these $P$. syringae pathovars (Melotto et al. 2006). To examine this possibility, we prepared suspensions of a subset of four of the pathovars (containing approximately $7 \times 10^{7} \mathrm{CFU} / \mathrm{ml}$ ) and dip-inoculated RG-prf3 plants. Five days later, distinct disease symptoms developed on leaves of each of the inoculated plants (Supplementary Figure S4).

The lesions caused by any particular pathovar had virtually identical characteristics on RG-pto11 and RG-prf3, although the overall symptoms were often more severe on RG-prf3 than
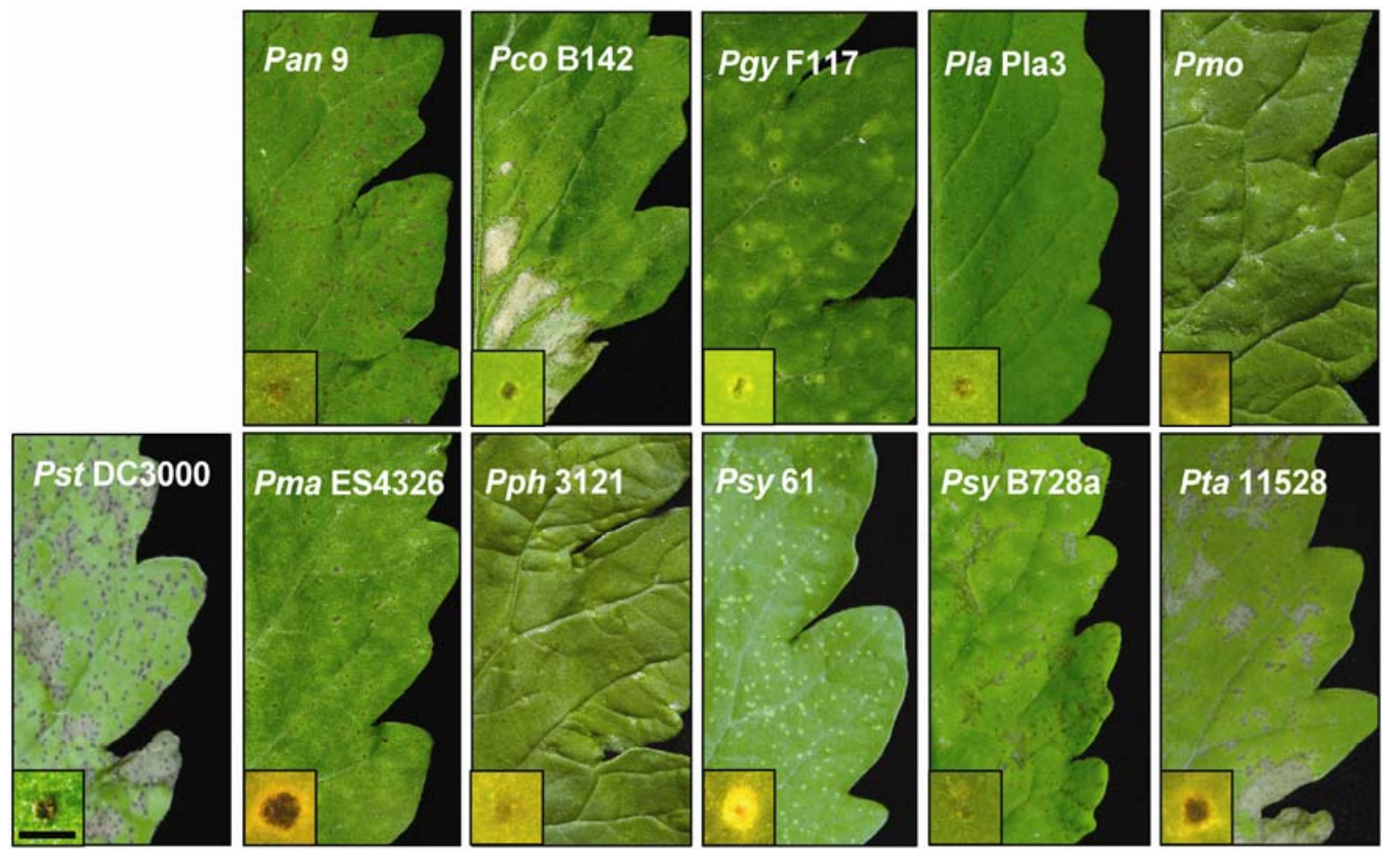

Fig. 2. Disease symptoms caused by various Pseudomonas syringae pathovars on leaves of tomato line RG-prf3. Leaves were infiltrated with the $P$. syringae strains indicated at $2 \times 10^{4} \mathrm{CFU} / \mathrm{ml}$. Photographs were taken 6 days after inoculation. Insets show close-up image of a single representative lesion taken with dissecting microscope. The black bar shown in the inset picture of $P$. syringae pv. tomato DC3000 represents $1 \mathrm{~mm}$ and the scale is the same for all photographs. 
on RG-pto11, especially in cases where the pathovars expressed AvrPto or AvrPtoB (Table 2). Interestingly, the appearance of the lesions varied greatly among the different $P$. syringae pathovars. For example, $P$. syringae pv. coronafaciens B142 caused pinpoint necrotic lesions without chlorosis; $P$. syringae pv. syringae 61 caused pale yellow spots with a central, lightbrown necrotic lesion; $P$. syringae pv. glycinea F117 caused necrotic lesions with a large chlorotic halo; and $P$. syringae pv. angulata 9 caused angular leaf spots reminiscent of the disease this pathovar causes on tobacco (Fig. 2). These observations indicate that many presumed nonhost $P$. syringae pathovars are capable of infecting tomato. Furthermore, they suggest that the broad array of disease symptoms caused by $P$. syringae pathovars on their normal hosts are due largely to the particular combination of virulence factors they express rather than to specific morphological or physiological characteristics of their plant hosts.

\section{Populations of the $P$. syringae pathovars increase significantly in tomato leaves, and Pto/Prf can restrict this growth.}

We next examined the extent to which the $P$. syringae pathovars are able to grow in leaves of the different tomato lines. Plants were vacuum infiltrated with a low-titer suspension $\left(10^{4} \mathrm{CFU} / \mathrm{ml}\right.$, corresponding to approximately $2 \times 10^{2} \mathrm{CFU} / \mathrm{cm}^{2}$ of leaf area) of the individual $P$. syringae pathovars and bacterial populations were measured 4 days later (Fig. 3; Supplementary Table S2). In the tomato line lacking Prf, we observed that the strains attained an average population of approximately $10^{5}$ $\mathrm{CFU} / \mathrm{cm}^{2}$ or higher at this timepoint. A nonpathogenic hrp and $h r c^{-}$mutant of DC3000 typically reaches no higher than $10^{3} \mathrm{CFU} / \mathrm{cm}^{2}$ in susceptible tomato leaves (Fouts et al. 2003) and an avirulent strain such as DC3000 on RG-PtoR grows to approximately $10^{4} \mathrm{CFU} / \mathrm{cm}^{2}$ (Fig. 3). Therefore, these data indicate that these pathovars can successfully multiply in tomato. Compared with RG-prf3, growth in RG-pto11 leaves was significantly less for 6 of the 10 pathovars (Fig. 3). The control strain, $P$. syringae pv. tomato DC3000, reached above $10^{7}$ $\mathrm{CFU} / \mathrm{cm}^{2}$ in RG-prf3 at day 4, suggesting that this strain carries additional virulence factors associated with its specific adaptation on tomato (Fig. 3).

All but one of the pathovars (i.e., P. syringae pv. phaseolicola 3121) which express either an avrPto or avrPtoB gene attained population levels significantly lower in the Pto/Prf-expressing line, RG-PtoR, than in RG-prf3 (Fig. 3). P. syringae pv. maculicola ES4326 also reached a lower population level on RG-PtoR compared with RG-prf3, although we had observed earlier that this strain did not trigger an HR on RG-PtoR and was able to cause disease symptoms on this line. $P$. syringae pv. maculicola ES4326 has two avrPtoB-related sequences, although they are both truncated (Guttman et al. 2002) and it is possible their proteins are either expressed in low abundance, unstable, or possibly partially masked by other effectors in $P$. syringae pv. maculicola ES4326. Interestingly, six of the eight pathovars which grew less well on RG-PtoR also reached a significantly lower population size on RG-pto11 compared with RG-prf3 (P. syringae pvs. angulata 9, maculicola ES4326, lachrymans 3, syringae B728a, mori, and tabaci 11528). Pto is a member of a small gene family and this difference might indicate that another Pto family member, whose activity is mediated through Prf, is able to recognize AvrPto or AvrPtoB homologs present in these six strains.

For $P$. syringae pv. coronafaciens $\mathrm{B} 142$ and $P$. syringae pv. syringae 61, which do not contain avrPto or avrPtoB, there was no significant difference in bacterial populations or disease symptoms among the tomato lines. This result is important because it demonstrates that these tomato lines do not differ in their general (basal) defense against these $P$. syringae pathovars.

We present a summary of our observations and define a "compatible" (C) interaction as one in which no HR is observed, disease symptoms form, and bacterial growth is higher compared with RG-PtoR (or when bacterial growth was similar in all three tomato genotypes) in Table 2 . A "partially compatible" (pC) interaction refers to certain interactions in which no HR was observed and disease symptoms formed; however, bacterial growth was not statistically significantly different than growth in RG-PtoR. In an "incompatible" interaction, early cell death is observed, no disease forms, and there is less bacterial growth compared with RG-prf3.

Our data show a striking correlation between the presence of AvrPto or AvrPtoB in a strain and its incompatibility with RGPtoR (Table 2). With one exception (P. syringae pv. phaseolicola NPS3121), all of these strains could form a compatible interaction with RG-prf3. The situation is less clear with the partially compatible interactions involving RG-pto11. In these cases, AvrPto- or AvrPtoB-expressing strains did not cause early cell

Table 2. Summary of the relationship between the gene-for-gene interaction and host-pathogen interaction for Pseudomonas syringae isolates

\begin{tabular}{|c|c|c|c|c|c|c|c|c|c|c|c|c|c|}
\hline \multirow[b]{2}{*}{ Isolate } & \multirow[b]{2}{*}{ avrPto or avrPtoB } & \multicolumn{3}{|c|}{ Ion leakage $^{\mathrm{v}}$} & \multicolumn{3}{|c|}{ Disease $^{w}$} & \multicolumn{3}{|c|}{ Growth $^{x}$} & \multicolumn{3}{|c|}{ Interaction $^{y}$} \\
\hline & & PtoR & pto11 & prf3 & PtoR & pto11 & prf3 & PtoR & pto11 & prf3 & PtoR & pto11 & prf3 \\
\hline angulata $\operatorname{Pan} 9$ & avrPtoB & + & - & - & - & + & ++ & $\mathrm{a}$ & $\mathrm{a}$ & $\mathrm{b}$ & $\mathrm{I}$ & $\mathrm{pC}$ & $\mathrm{C}$ \\
\hline coronafaciens B142 & Neither & - & - & - & + & + & + & $\mathrm{a}$ & $\mathrm{a}$ & $\mathrm{a}$ & $\mathrm{C}$ & $\mathrm{C}$ & $\mathrm{C}$ \\
\hline glycinea $\mathrm{F} 117$ & avrPtoB & + & - & - & - & + & + & $\mathrm{a}$ & $\mathrm{b}$ & $\mathrm{b}$ & $\mathrm{I}$ & $\mathrm{C}$ & $\mathrm{C}$ \\
\hline lachrymans $\mathrm{Pla} 3$ & Both & + & - & - & - & + & ++ & $\mathrm{a}$ & $\mathrm{a}$ & $\mathrm{b}$ & I & $\mathrm{pC}$ & $\mathrm{C}$ \\
\hline mori PDDCC4331 & Both & + & - & - & - & + & + & $\mathrm{a}$ & $\mathrm{a}$ & $\mathrm{b}$ & $\mathrm{I}$ & $\mathrm{pC}$ & $\mathrm{C}$ \\
\hline maculicola ES4326 & Neither $^{\mathrm{Z}}$ & - & - & - & + & + & + & $\mathrm{a}$ & $\mathrm{a}$ & $\mathrm{b}$ & $\mathrm{C}$ & $\mathrm{C}$ & $\mathrm{C}$ \\
\hline phaseolicola NPS3121 & Both & + & - & - & - & + & + & $\mathrm{a}$ & $\mathrm{a}$ & a & I & $\mathrm{pC}$ & $\mathrm{pC}$ \\
\hline syringae 61 & Neither & - & - & - & + & + & + & $\mathrm{a}$ & $\mathrm{a}$ & $\mathrm{a}$ & $\mathrm{C}$ & $\mathrm{C}$ & $\mathrm{C}$ \\
\hline syringae $\mathrm{B} 728 \mathrm{a}$ & Both & + & - & - & - & + & ++ & $\mathrm{a}$ & $\mathrm{b}$ & $\mathrm{c}$ & I & $\mathrm{C}$ & $\mathrm{C}$ \\
\hline tabaci 11528 & avrPtoB & + & - & - & - & + & ++ & $\mathrm{a}$ & $\mathrm{a}$ & $\mathrm{b}$ & $\mathrm{I}$ & $\mathrm{pC}$ & $\mathrm{C}$ \\
\hline tomato DC3000 & Both & + & - & - & - & + & + & $\mathrm{a}$ & $\mathrm{b}$ & b & I & $\mathrm{C}$ & $\mathrm{C}$ \\
\hline
\end{tabular}

${ }^{v}$ Symbols: $+=$ enhanced electrolyte leakage from leaves associated with the hypersensitive response and $-=$ no enhanced electrolyte leakage. PtoR $=$ Rio Grande (RG) PtoR (Pto/Pto, Prf/Prf), pto11 = RG-pto11 (pto11/pto11, Prf/Prf), and prf3 = RG-prf3 = (Pto/Pto, prf3/prf3).

${ }^{\mathrm{w}}$ Symbols: $++=$ severe disease symptoms observed, $+=$ disease symptoms, and $-=$ no disease symptoms observed.

${ }^{x}$ Same letter assigned for tomato lines within a pathovars indicates no difference at a significance level of $5 \%$.

${ }^{\mathrm{y}} \mathrm{I}=$ incompatible interaction: enhanced ion leakage; no disease, and, with one exception (NPS3121), less growth compared with RG-prf3. pC = partially compatible interaction: no enhanced ion leakage and disease symptoms were observed; however, bacterial growth was not different than RG-PtoR. $\mathrm{C}=$ compatible interaction: for $P$. syringae pv. coronafacien B142, P. syringae pv. maculicola ES4326, and $P$. syringae pv. syringae 61 , similar results with all assays were observed with all tomato genotypes. For the other strains, on RG-pto11 and RG-prf3, C indicates no enhanced ion leakage and disease symptoms were observed; bacterial growth was statistically significantly higher than in RG-PtoR.

${ }^{\text {z }}$ Pma ES4326 expresses hopPmaL and holPmaN, C-terminus truncated forms of AvrPtoB (Guttman et al. 2002). 
death and disease symptoms formed; however, nevertheless, the strains were restricted in their growth to levels not different from that in RG-PtoR. This partial compatibility may be due to other Pto family members which recognize certain forms of AvrPto or AvrPtoB in a Prf-dependent manner and activate weaker defense responses (Abramovitch et al. 2003). In summary, our data suggest that a recognition event mediated by various Pto family members in concert with the Prf protein plays a role in restricting the ability of AvrPto- or AvrPtoB-expressing P. syringae pathovars from infecting tomato leaves.

\section{Expression of AvrPto and AvrPtoB \\ in $P$. syringae 61 restricts ability of this strain \\ to cause disease in Pto/Prf-expressing tomato.}

To further confirm that these $P$. syringae pathovars are growing in tomato leaves and that their growth can be restricted by Pto/Prf, we selected one pathovar, P. syringae pv. syringae 61, which lacks AvrPto and AvrPtoB, for further experiments. We cloned the avrPto genes from $P$. syringae pv. tomato JL1065 or the avrPtoB gene from $P$. syringae pv. tomato DC3000 into a broad host-range vector and introduced them individually into $P$. syringae pv. syringae 61. Inoculation of a control $P$. syringae pv. syringae 61 strain carrying an empty vector caused the formation of pale yellow spots on all of the tomato lines and the strain grew to approximately $10^{5} \mathrm{CFU} / \mathrm{cm}^{2}$ (Fig. 4). However, $P$. syringae pv. syringae 61 strains expressing either of the effectors elicited an HR (not shown) on RG-PtoR leaves, caused no disease symptoms, and grew to statistically significantly lower population levels on this tomato line (Fig. 4). All of the strains caused disease symptoms and grew to similar levels on RG-pto11 and RG-prf3, with the exception of $P$. syringae pv. syringae 61(avrPtoB $)$, which appeared to be weakly recognized by RG-pto11, probably by another Pto family member expressed in this line. Therefore, these data further support the notion that $P$. syringae pv. syringae 61 can infect tomato and its growth can be restricted by the presence of the Pto/Prf-AvrPto/AvrPtoB gene-for-gene interaction.

\section{DISCUSSION}

The large number of pathovars of $P$. syringae provides an extraordinary example of host-range specificity in plant-pathogen interactions (Rudolph 1995). The molecular mechanisms underlying pathogen adaptation to a specific host and nonhost resistance are poorly understood and our data shed light on two forces that appear to contribute to these phenomena. First, we found that many presumed nonhost $P$. syringae pathovars can, in fact, cause disease symptoms on tomato and attain fairly high population levels. However, they do not reach the population levels of $P$. syringae pv. tomato strains. This suggests that these $P$. syringae pathovars may lack specific virulence factors, including perhaps key type III effectors, which are expressed by $P$. syringae pv. tomato and specially adapted for growth on tomato leaves. A second mechanism, which our work suggests limits growth of $P$. syringae pathovars in tomato, is recognition of the type III effectors AvrPto and AvrPtoB by Pto family members and Prf. The pathway activated by Pto family members acting through Prf confers strong host resistance to AvrPto- or AvrPtoB-expressing races of P. syringae pv. tomato, which limits pathogen growth and inhibits formation of bacterial speck symptoms. Because functional Pto and $\operatorname{Prf}$ genes are widespread among wild tomato species and other solanaceous species and avrPto or avrPtoB genes are present in many $P$. syringae pathovars, our data suggest that recognition mediated by Pto family members and Prf might play a broad role in restricting the ability of many $P$. syringae pathovars from infecting these plants in natural settings.
Nonhost resistance typically is defined as resistance in an entire plant species against all members of a given pathogen taxon (Goodman and Novacky 1994; Mysore and Ryu 2004; Thordal-Christensen 2003). In the case of $P$. syringae, the infrasubspecific classification "pathovar" is used to account for the specific host ranges which organisms in this species display (Agrios 1997; Young et al. 1992). Thus, tomato is considered to be a nonhost for $P$. syringae pathovars except for $P$. syringae pv. tomato and, to a lesser extent, $P$. syringae pv. syringae (Jones 1991). However, we have shown here that many $P$. syringae pathovars actually have the fundamental ability to infect tomato. These infections, though, can be severely restricted by the presence in the plant of a functional Pto or Prf pathway and in the pathovar of either AvrPto or AvrPtoB. Such gene-for-gene interactions originally were defined as determinants of pathogen host range at the pathovar-species and race-
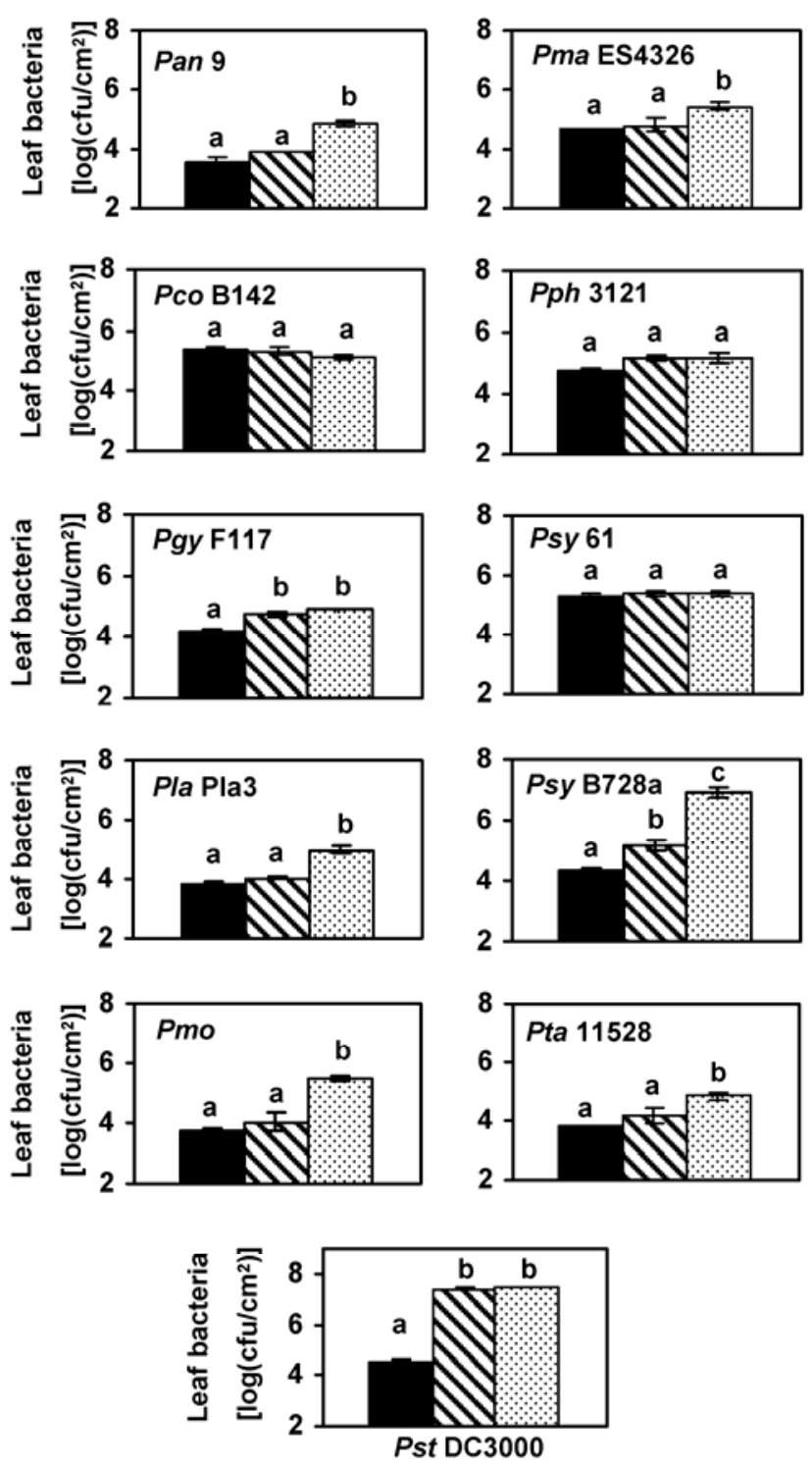

Fig. 3. Growth of Pseudomonas syringae strains in tomato leaves. The $P$. syringae strains indicated were vacuum infiltrated $\left(10^{4} \mathrm{CFU} / \mathrm{ml}\right)$ into leaves of Rio Grande tomato lines RG-PtoR (black), RG-pto11 (hatched), or RG-prf3 (gray) and bacterial populations were measured 4 days later. Bars indicate standard errors. Experiments presented in this figure were performed twice with similar results. The data from the two experiments were treated as replicates and were analyzed using Duncan's multiple range test. Means with the same letter assigned for each pathovar are not different at a significance level of $5 \%$. 
cultivar levels (Ellingboe 1976; Lorang et al. 1994). However, our data indicate that $R$-gene-mediated resistance also might govern pathogen host range at the pathovar-cultivar level.

Pto is a member of a clustered gene family consisting of five or six members depending on the tomato species (Pedley and Martin 2003; Riely and Martin 2001). Pto itself is not present in any known accession of cultivated tomato ( $S$. lycopersicum); however, paralogous members of the family reside at the same chromosomal region of this species. In this regard, it is interesting that RG-pto11, despite having a mutation creating a nonfunctional Pto kinase, still appeared to retain the ability to restrict growth of certain $P$. syringae pathovars expressing AvrPto or AvrPtoB (note that the RG lines all have the $S$. pimpinellifolium Pto haplotype). This observation suggests that other Pto family members are able to recognize forms of these type III effectors present in these pathovars. In this regard, we have reported previously that a Prf-dependent resistance referred to as Rsb can activate defenses in response to certain forms of AvrPtoB (Abramovitch et al. 2003). These considerations raise the possibility that cultivated tomato (and perhaps all species of tomato) may express Pto-like genes which confer some resistance to avrPto- and avrPtoB-expressing $P$. syringae pathovars. Critical testing of this potentially more general involvement of Pto family members in nonhost resistance would require an S. lycopersicum line lacking a functional Prf gene, and such a line is not presently available (note that the
RG-prf3 line we used carries the haplotype from S. pimpinellifolium).

Further support for gene-for-gene interactions playing an important role in nonhost resistance comes from recent work with $P$. syringae pv. tomato DC3000 and its nonhost $N$. benthamiana. In that system, it has been found that one DC3000 type III effector elicits an SGT1-mediated HR in N. benthamiana leaves (Wei et al. in press). Deletion of this effector from DC3000 allows the pathogen to grow and cause disease on $N$. benthamiana leaves. Interestingly, deletion of certain additional effectors from this now-virulent DC3000 strain mitigates its virulence, not only on $N$. benthamiana but also on tomato and Arabidopsis, suggesting that the activity of at least some effectors is not plant species-specific but, rather, broadly adapted to plant tissues (Wei et al. in press).

Although we have shown that certain $P$. syringae pathovars can infect tomato in an experimental setting, these pathovars apparently have not been observed to cause disease on tomato in agricultural settings and it is possible that such infections do not occur. Alternatively, these pathovars might infect tomato plants in the field but, because of the low population levels they attain in leaves compared with $P$. syringae pv. tomato strains, they may fail to produce noticeable disease symptoms. If such "low-grade" infections do occur, it is possible they could have subtle detrimental effects on tomato yields. This possibility could be testable, given that $P$. syringae pathovars

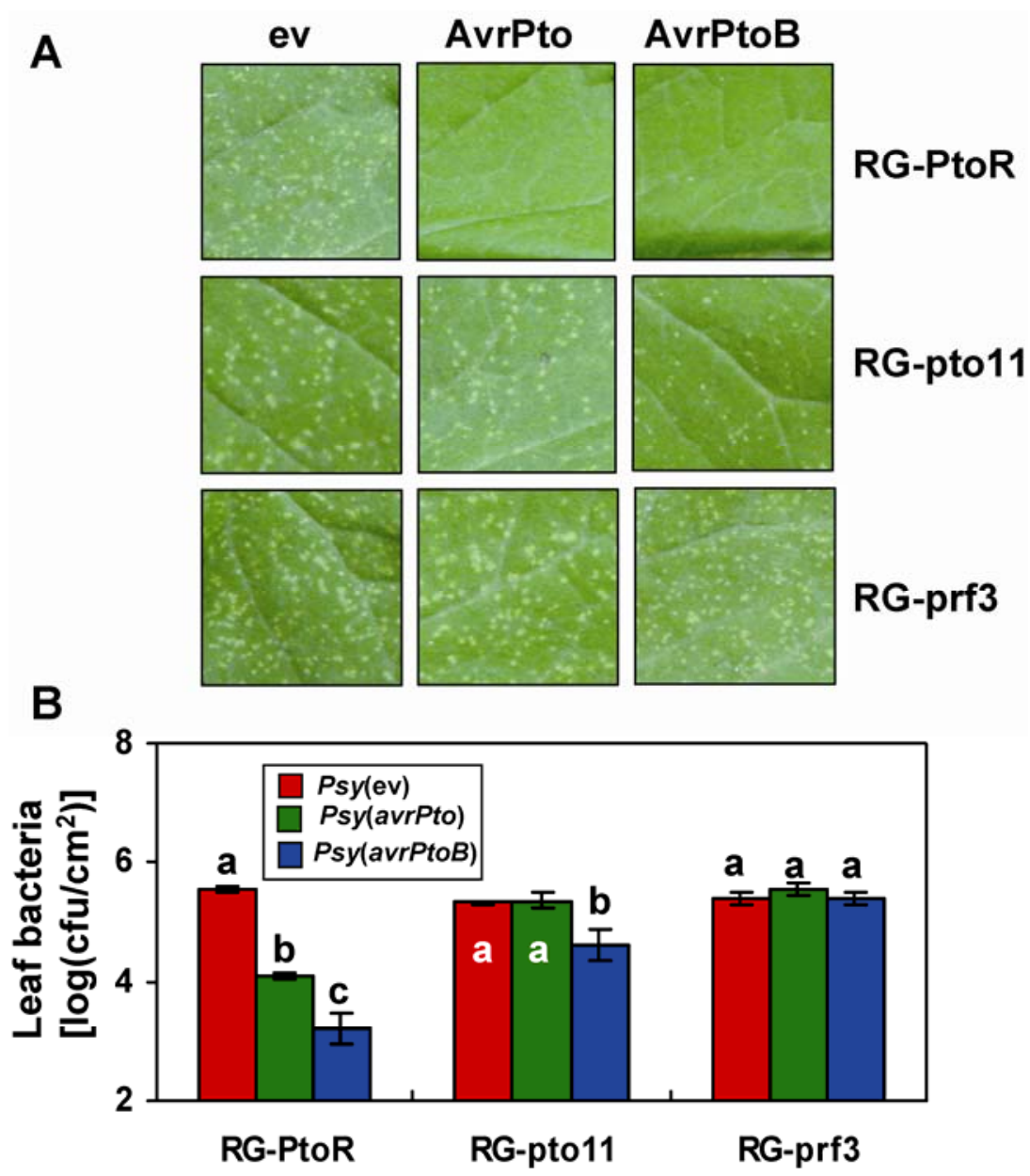

Fig. 4. Response of tomato leaves to Pseudomonas syringae pv. syringae 61 expressing P. syringae pv. tomato DC3000 alleles of avrPto or avrPtoB. A, Leaves were vacuum infiltrated with the strains indicated at $2 \times 10^{4} \mathrm{CFU} / \mathrm{ml}$ and photographs of $1-\mathrm{cm}^{2}$ areas were taken through a dissecting microscope 4 days later. B, P. syringae pv. syringae 61 strains expressing the genes indicated were vacuum infiltrated $\left(2 \times 10^{4} \mathrm{CFU} / \mathrm{ml}\right)$ into leaves of Rio Grande tomato lines RG-PtoR, RG-pto11, or RG-prf3 and bacterial populations were measured 4 days later. Bars indicate the standard errors; ev $=$ empty vector (pCPP45). Experiments presented in this figure were performed twice with similar results. The data from the two experiments were treated as replicates and were analyzed using Duncan's multiple range test. Means with the same letter assigned for each pathovar are not different at a significance level of 5\%. 
are widespread in the environment and the Pto gene is now deployed in 16 of the top 20 tomato processing cultivars and on approximately $60 \%$ of tomato acreage in California (Pedley and Martin 2003).

In the early days after $R$ genes were molecularly cloned, it was hoped they might function in diverse unrelated plant species and, therefore, be broadly useful as a transgenic crop protection strategy (Martin et al. 2003). However, $R$ genes have been found to work only among plants within the same family from which they were isolated (e.g., Rxol) (Zhao et al. 2005) - possibly reflecting the requirement of other family-specific proteins as part of the recognition complex (Martin 1999). In addition, the recognition specificity of $\mathrm{R}$ proteins for effector molecules present only in pathogens adapted to the species from which the $R$ gene was isolated may limit the usefulness of a transgenic application of $R$ genes. However, because avrPto and $a v r P t o B$ are now known to be widely distributed among $P$. syringae pathovars, the transgenic expression of Pto in other solanaceous species might be worthwhile. For example, our work suggests that transgenic expression of Pto in tobacco might be an effective control for blackfire and wildfire disease in tobacco if avrPto and $a v r P t o B$ are found to be present in common field isolates species of $P$. $s y$ ringae pvs. angulata and tabaci.

We found that, despite the ability of many $P$. syringae pathovars to grow in tomato leaves, they did not reach the high population levels of $P$. syringae pv. tomato. It is possible that certain type III effectors in these pathovars are weakly recognized by other $\mathrm{R}$ proteins in tomato, thus restricting their growth. Alternatively, it is possible that $P$. syringae pv. tomato strains have evolved specific effectors for colonization and growth in tomato tissues and these effectors are lacking in other $P$. syringae pathovars. A similar explanation was put forth recently for $P$. syringae pv. syringae B728a based on the activities of various type III effectors from that strain on different plant hosts and nonhosts (Vinatzer et al. 2006). There currently are few well-characterized examples of such host range-broadening type III effectors (e.g., HsvB and HsvG) (Nissan et al. 2006) and the availability of the complete set of approximately 30 type III effectors from $P$. syringae pv. tomato DC3000 now will allow a concerted strategy of transforming into a nonadapted $P$. syringae pathovar each of the DC3000 effectors to test for ones that promote growth specifically in tomato leaves.

Finally, the pathovars we examined cause distinct disease symptoms on their usual host plants, denoted by such names as angular leaf spot (P. syringae pvs. angulata and lachrymans), halo blight ( $P$. syringae pv. phaseolicola), and wildfire $(P$. syringae pv. tabaci). It is formally possible that the physiological or structural features of the host leaf play an important role in the formation of the disease symptoms caused by these pathogens. However, we found that each of the pathovars we examined displayed distinct symptoms which, in many cases, were reminiscent of symptoms that occur in the normal host (e.g., $P$. syringae pv. angulata caused angular leaf spots on tomato). These observations suggest that the unique array of virulence factors (e.g., toxins and perhaps type III effectors) which each pathovar expresses plays a more important role in the appearance of disease symptoms than does the specific physiological or structural features attributes of the plant host.

\section{MATERIALS AND METHODS}

\section{DNA, RNA, and protein gel blot analysis.}

Genomic DNA ( $2 \mu \mathrm{g})$ digested with ClaI and total RNA (20 $\mu \mathrm{g}$ ) isolated from bacteria grown in rich medium and hrpminimal medium were used for DNA and RNA gel blot analysis, respectively, following procedures described previously (Fouts et al. 2002; Lin and Martin 2005). Expression of AvrPto and AvrPtoB protein was detected using anti-AvrPto and antiAvrPtoB antibodies following standard techniques for protein gel blot analysis (Sambrook et al. 1989).

A $0.7-\mathrm{kb}$ fragment containing the hrp-box from avrPto, the open reading frame of avrPto, and the 200-bp downstream sequence of avrPto was polymerase chain reaction amplified using the forward primer 5'-GGTGTGATGGAACTCTTTCCTGCT C-3' and reverse primer 5'-TCAG-GGGACTATTCTAAAAGC$3^{\prime}$, and cloned into pCR2.1 (Invitrogen Corp., Carlsbad, CA, U.S.A.). The KpnI/XbaI fragment from pCR2.1 was cloned into the broad-host-range vector, pCPP45, to create pavrPto. pavrPto and previously constructed pavrPtoB (Lin and Martin 2005) were introduced into $P$. syringae pv. syringae strain 61 by triparental mating to obtain strains 61(avrPto) and 61(avrPtoB). Empty vector (ev; pCPP45) also was introduced into $P$. syringae pv. syringae 61 to generate $61(\mathrm{ev})$ as a control.

\section{Ion leakage assays.}

Leaf disks excised from the area infiltrated with the Pseudomonas strains (optical density at $600 \mathrm{~nm}=0.05$; approximately $2 \times 10^{7} \mathrm{CFU} / \mathrm{ml}$ ) at the times indicated were incubated in water at room temperature for $1 \mathrm{~h}$. This solution was used to measure sample conductivity (in microSiemens) with an Acorn series CON5 meter (Oakton Instruments, Vernon Hills, IL, U.S.A.). Leaf disks taken from areas without infiltration with Pseudomonas strains were used as a blank control to normalize sample conductivity. Ion leakage is represented as the conductivity difference between the samples and the blank control. Experiments were performed twice and the combined data were analyzed using Duncan's multiple range test.

Disease assays and Pseudomonas population measurements.

Tomato (S. lycopersicum) plants were grown as described previously (Kim et al. 2002). Three genotypes of tomato cv. Rio Grande (RG) were used in this study: RG-PtoR (Pto/Pto, Prf/Prf), RG-pto11 (pto11/pto11, Prf/Prf), and RG-prf3 (Pto/Pto, prf3/prf3) (Salmeron et al. 1994). RG-PtoR carries the Pto/Prf region from $S$. pimpinellifolium introgressed into an $S$. lycopersicum background. RG-pto11 and RG-prf3 were derived by mutagenesis of RG-PtoR (Salmeron et al. 1994).

$P$. syringae strains were grown in King's B (KB) medium (King et al. 1954) at $30^{\circ} \mathrm{C}$. For pathogenicity assays, bacterial suspensions of $2 \times 10^{4} \mathrm{CFU} / \mathrm{ml}$ in $10 \mathrm{mM} \mathrm{MgCl}$ and $0.002 \%$ Silwet L-77 (Crompton Co., Middlebury, CT, U.S.A.) were vacuum infiltrated into leaves of 4-week-old plants. Disease development and bacterial populations were monitored every other day after inoculation. Bacteria recovered from plants were plated on $\mathrm{KB}$ medium containing rifampicin $(100 \mu \mathrm{g} / \mathrm{ml})$. Fully expanded leaflets were used for recovery of bacteria (Lin and Martin 2005). Experiments were performed twice and the combined data were analyzed using Duncan's multiple range test. For the dip-inoculation experiments, approximately $7 \times$ $10^{7} \mathrm{CFU} / \mathrm{ml}$ in $10 \mathrm{mM} \mathrm{MgCl}_{2}$ and $0.025 \%$ Silwet L-77 was used and the photographs were taken 5 days after dipping.

\section{ACKNOWLEDGMENTS}

We thank A. Collmer and D. Cuppels for their kind gifts of strains of $P$. syringae pathovars; A. Collmer, K. Mysore, K. Munkvold, and T. Rosebrock for comments on the manuscript; and B. Randall and T. Rosebrock for the dip-inoculation experiments. This work was supported by National Science Foundation grant number DBI-0605059 and United States Department of Agriculture and National Research Institute grant no. 2005-35301-15675.

\section{LITERATURE CITED}

Abramovitch, R. B., Kim, Y.-J., Chen, S., Dickman, M. B., and Martin, G. B. 2003. Pseudomonas type III effector AvrPtoB induces plant disease 
susceptibility by inhibition of host programmed cell death. EMBO (Eur. Mol. Biol. Organ.) J. 22:60-69.

Abramovitch, R. B., Anderson, J. C., and Martin, G. B. 2006. Bacterial elicitation and evasion of plant innate immunity. Nat. Rev. Mol. Cell. Biol. 7:601-611.

Agrios, G. N. 1997. Plant Pathology. Academic Press, San Diego, CA, U.S.A.

Buell, C. R., Joardar, V., Lindeberg, M., Selengut, J., Paulsen, I. T., Gwinn, M. L., Dodson, R. J., Deboy, R. T., Durkin, A. S., Kolonay, J. F., Madupu, R., Daugherty, S., Brinkac, L., Beanan, M. J., Haft, D. H., Nelson, W. C., Davidsen, T., Zafar, N., Zhou, L., Liu, J., Yuan, Q., Khouri, H., Fedorova, N., Tran, B., Russell, D., Berry, K., Utterback, T., Van Aken, S. E., Feldblyum, T. V., D'Ascenzo, M., Deng, W. L., Ramos, A. R., Alfano, J. R., Cartinhour, S., Chatterjee, A. K., Delaney, T. P., Lazarowitz, S. G., Martin, G. B., Schneider, D. J., Tang, X., Bender, C. L., White, O., Fraser, C. M., and Collmer, A. 2003. The complete genome sequence of the Arabidopsis and tomato pathogen Pseudomonas syringae pv. tomato DC3000. Proc. Natl. Acad. Sci. U.S.A. 100:10181-10186.

Chakrabarty, P. K., and Gabriel, D. W. 1997. Cloning and characterization of a member of the Xanthomonas avr/pth gene family that evades all commercially utilized cotton I genes in the United States. Phytopathology 87:1160-1167.

Cohn, J. R., and Martin, G. B. 2005. Pseudomonas syringae pv. tomato type III effectors AvrPto and AvrPtoB promote ethylene-dependent cell death in tomato. Plant J. 44:139-154.

Dangl, J. L., Ritter, C., Gibbon, M. J., Mur, L. A. J., Wood, J. R., Goss, S., Mansfield, J., Taylor, J. D., and Vivian, A. 1992. Functional homologs of the Arabidopsis RPM1 disease resistance gene in bean and pea. Plant Cell 4:1359-1369.

Ellingboe, A. H. 1976. Genetics of host-parasite interactions. Pages 761778 in: Encyclopedia of Plant Pathology, New Series, Vol. 4. J. Wiley and Sons Press, Inc., New York.

Fouts, D. E., Abramovitch, R. B., Alfano, J. R., Baldo, A. M., Buell, C. R., Cartinhour, S., Chatterjee, A. K., D'Ascenzo, M., Gwinn, M. L., Lazarowitz, S. G., Lin, N. C., Martin, G. B., Rehm, A. H., Schneider, D. J., van Dijk, K., Tang, X., and Collmer, A. 2002. Genomewide identification of Pseudomonas syringae pv. tomato DC3000 promoters controlled by the HrpL alternative sigma factor. Proc. Natl. Acad. Sci. U.S.A. 99:2275-2280.

Fouts, D. E., Badel, J. L., Ramos, A. R., Rapp, R. A., and Collmer, A. 2003. A Pseudomonas syringae pv. tomato DC3000 Hrp (Type III secretion) deletion mutant expressing the Hrp system of bean pathogen $P$. syrinage pv. syringae 61 retains normal host specificity for tomato. Mol. Plant-Microbe Interact. 16: 43-52.

Goodman, R. N., and Novacky, A. J. 1994. Pages 117-173 in: The Hypersensitive Reaction in Plants to Pathogens: A Resistance Phenomenon. The American Phytopathological Society Press, St. Paul, MN, U.S.A.

Guttman, D. S., Vinatzer, B. A., Sarkar, S. F., Ranall, M. V., Kettler, G., and Greenberg, J. T. 2002. A functional screen for the type III (Hrp) secretome of the plant pathogen Pseudomonas syringae. Science 295:1722-1726.

He, P., Shan, L., Lin, N. C., Martin, G. B., Kemmerling, B., Nurnberger, T., and Sheen, J. 2006. Specific bacterial suppressors of MAMP signaling upstream of MAPKKK in Arabidopsis innate immunity. Cell $125: 563-575$

He, X., Anderson, J. C., Pozo Od, O., Gu, Y. Q., Tang, X., and Martin, G. B. 2004. Silencing of subfamily I of protein phosphatase 2A catalytic subunits results in activation of plant defense responses and localized cell death. Plant J. 38:563-577.

Hirano, S. S., and Upper, C. D. 2000. Bacteria in the leaf ecosystem with emphasis on Pseudomonas syringae - a pathogen, ice nucleus, and epiphyte. Microbiol. Mol. Biol. Rev. 64:624-653.

Jackson, R. W., Mansfield, J. W., Ammouneh, H., Dutton, L. C., Wharton, B., Ortiz-Barredo, A., Arnold, D. L., Tsiamis, G., Sesma, A., Butcher, D., Boch, J., Kim, Y.-J., Martin, G. B., Tegli, S., Murillo, J., and Vivian, A. 2002. Location and activity of members of a family of virPphA homologues in pathovars of Pseudomonas syringae and $P$. savastanoi. Mol. Plant Pathol. 3:205-216.

Joardar, V., Lindeberg, M., Jackson, R. W., Selengut, J., Dodson, R., Brinkac, L. M., Daugherty, S. C., Deboy, R., Durkin, A. S., Giglio, M. G., Madupu, R., Nelson, W. C., Rosovitz, M. J., Sullivan, S., Crabtree, J., Creasy, T., Davidsen, T., Haft, D. H., Zafar, N., Zhou, L., Halpin, R., Holley, T., Khouri, H., Feldblyum, T., White, O., Fraser, C. M., Chatterjee, A. K., Cartinhour, S., Schneider, D. J., Mansfield, J., Collmer, A., and Buell, C. R. 2005. Whole-genome sequence analysis of Pseudomonas syringae pv. phaseolicola 1448A reveals divergence among pathovars in genes involved in virulence and transposition. $\mathbf{J}$. Bacteriol. 187:6488-6498.

Jones, J. B. 1991. Bacterial speck. Pages 26-27 in: Compendium of To- mato Diseases. J. B. Jones, J. P. Jones, R. E. Stall, and T. A. Zitter, eds. American Phytopathological Society Press, St. Paul, MN, U.S.A.

Keen, N. T. 1988. Host range determinants in plant pathogens and symbionts. Annu. Rev. Microbiol. 42:421-440.

Kim, Y.-J., Lin, N.-C., and Martin, G. B. 2002. Two distinct Pseudomonas effector proteins interact with the Pto kinase and activate plant immunity. Cell 109:589-598

King, E., Ward, M., and Raney, D. 1954. Two simple media for the demonstration of pyocyanin and fluorescin. J. Lab. Clin. Med. 44:301-307.

Kobayashi, D. Y., Tamaki, S. J., and Keen, N. T. 1989. Cloned avirulence genes from the tomato pathogen Pseudomonas syringae pv. tomato confer cultivar specificity on soybean. Proc. Natl. Acad. Sci. U.S.A. 86:157-161.

Lin, N.-C., and Martin, G. B. 2005. An avrPto/avrPtoB mutant of Pseudomonas syringae pv. tomato DC3000 does not elicit Pto-mediated resistance is less virulent on tomato. Mol. Plant-Microbe Interact. 18:43-51.

Lin, N. C., Abramovitch, R. B., Kim, Y. J., and Martin, G. B. 2006. Diverse AvrPtoB homologs from several Pseudomonas syringae pathovars elicit Pto-dependent resistance and have similar virulence activities. Appl. Environ. Microbiol. 72:702-712.

Lindeberg, M., Cartinhour, S., Myers, C. R., Schechter, L. M., Schneider, D. J., and Collmer, A. 2006. Closing the circle on the discovery of genes encoding Hrp regulon members and type III secretion system effectors in the genomes of three model Pseudomonas syringae strains. Mol. Plant-Microbe Interact. 19:1151-1158.

Lorang, J. M., Shen, H., Kobayashi, D., Cooksey, D., and Keen, N. T. 1994. avrA and avrE in Pseudomonas syringae pv. tomato PT23 play a role in virulence on tomato plants. Mol. Plant-Microbe Interact. 7:508515.

Lu, M., Tang, X., and Zhou, J. M. 2001. Arabidopsis NHO1 is required for general resistance against Pseudomonas bacteria. Plant Cell 13:437447.

Martin, G. B. 1999. Functional analysis of plant disease resistance genes and their downstream effectors. Curr. Opin. Plant Biol. 2:273-279.

Martin, G. B., Bogdanove, A. J., and Sessa, G. 2003. Understanding the functions of plant disease resistance proteins. Annu. Rev. Plant Biol. 54:23-61.

Melotto, M., Underwood, W., Koczan, J., Nomura, K., and He, S. Y. 2006. Plant stomata function in innate immunity against bacterial invasion. Cell 126:969-980.

Mucyn, T. S., Clemente, A., Andriotis, V. M., Balmuth, A. L., Oldroyd, G. E., Staskawicz, B. J., and Rathjen, J. P. 2006. The tomato NBARC-LRR protein Prf interacts with Pto kinase in vivo to regulate specific plant immunity. Plant Cell 18.

Mysore, K. S., and Ryu, C. M. 2004. Nonhost resistance: How much do we know? Trends Plant Sci. 9:97-104.

Nissan, G., Manulis-Sasson, S., Weinthal, D., Mor, H., Sessa, G., and Barash, I. 2006. The type III effectors HsvG and HsvB of gall-forming Pantoea agglomerans determine host specificity and function as transcriptional activators. Mol. Microbiol. 61:1118-1131.

Peart, J. R., Lu, R., Sadanandom, A., Malcuit, I., Moffett, P., Brice, D. C., Schauser, L., Jaggard, D. A., Xiao, S., Coleman, M. J., Dow, M., Jones, J. D., Shirasu, K., and Baulcombe, D. C. 2002. Ubiquitin ligase-associated protein SGT1 is required for host and nonhost disease resistance in plants. Proc. Natl. Acad. Sci. U.S.A. 99:10865-10869.

Pedley, K. F., and Martin, G. B. 2003. Molecular basis of Pto-mediated resistance to bacterial speck disease in tomato. Annu. Rev. Phytopathol. 41:215-243.

Preston, G. M. 2000. Pseudomonas syringae pv. tomato: The right pathogen, of the right plant, at the right time. Mol. Plant Pathol. 1:263-275.

Riely, B. K., and Martin, G. B. 2001. Ancient origin of pathogen recognition specificity conferred by the tomato disease resistance gene Pto. Proc. Natl. Acad. Sci. U.S.A. 98:2059-2064.

Rose, L. E., Langley, C. H., Bernal, A. J., and Michelmore, R. W. 2005. Natural variation in the Pto pathogen resistance gene within species of wild tomato (Lycopersicon). I. Functional analysis of Pto alleles. Genetics 171:345-357.

Rudolph, K. W. E. 1995. Pseudomonas syringae pathovars. Pages 47-138 in: Pathogenesis and Host Specificity in Plant Diseases, Vol. 1: Prokaryotes. U. S. Singh, R. P. Singh, and K. Kohmoto, eds. Elsevier Science Inc., Tarrytown, NY, U.S.A.

Salmeron, J. M., Barker, S. J., Carland, F. M., Mehta, A., Y., and Staskawicz, B. J. 1994. Tomato mutants altered in bacterial disease resistance provide evidence for a new controlling pathogen recognition. Plant Cell 6:511-520.

Salmeron, J. M., Oldroyd, G. E. D., Rommens, C. M. T., Scofield, S. R., Kim, H.-S., Lavelle, D. T., Dahlbeck, D., and Staskawicz, B. J. 1996. Tomato $\operatorname{Prf}$ is a member of the leucine-rich repeat class of plant disease resistance genes and lies embedded within the Pto kinase gene cluster. Cell 86:123-133. 
Sambrook, J., Fritsch, E. F., and Maniatis, T. 1989. Molecular Cloning: A Laboratory Manual. Cold Spring Harbor Laboratory Press, Cold Spring Harbor, NY, U.S.A.

Sarkar, S. F., and Guttman, D. S. 2004. Evolution of the core genome of Pseudomonas syringae, a highly clonal, endemic plant pathogen. Appl. Environ. Microbiol. 70:1999-2012.

Sarkar, S. F., Gordan, J. S., Martin, G. B., and Guttman, D. S. 2006. Comparative genomics of host-specific virulence in Pseudomonas syringae. Genetics 174:1041-1056.

Swarup, S., De Feyter, R., Brlansky, R. H., and Gabriel, D. W. 1991. A pathogenicity locus from Xanthomonas citri enables strains from several pathovars of $X$. campestris to elicit cankerlike lesions on citrus. Phytopathology 81:802-809.

Thilmony, R. T., Chen, Z., Bressan, R. A., and Martin, G. B. 1995. Expression of the tomato Pto gene in tobacco enhances resistance to Pseudomonas syringae pv. tabaci expressing avrPto. Plant Cell 7:1529-1536.

Thordal-Christensen, H. 2003. Fresh insights into processes of nonhost resistance. Curr. Opin. Plant Biol. 6:351-357.

Vinatzer, B. A., Teitzel, G. M., Lee, M. W., Jelenska, J., Hotton, S., Fairfax K., Jenrette, J., and Greenberg, J. T. 2006. The type III effector repertoire of Pseudomonas syringae pv. syringae B728a and its role in survival and disease on host and non-host plants. Mol. Microbiol. 62:26-44.

Vivian, A., and Mansfield, J. 1993. A proposal for a uniform genetic nomenclature for avirulence genes in phytopathogenic Pseudomonads. Mol. Plant-Microbe Interact. 6:9-10.

Vleeshouwers, V. G., Martens, A., van Dooijeweert, W., Colon, L. T., Govers, F., and Kamoun, S. 2001. Ancient diversification of the Pto kinase family preceded speciation in Solanum. Mol. Plant-Microbe Interact. 14:996-1005.

Wei, C.-F., Kvitko, B. H., Shimizu, R., Crabill, E., Alfano, J. R., Lin, N. C., Martin, G. B., Huang, H.-C., and Collmer, A. A Pseudomonas syringae pv. tomato DC3000 mutant lacking the type III effector HopQ1-1 is able to cause disease in the model plant Nicotiana benthamiana. Plant J. In press.

Young, J. M., Takikawa, Y., Gardan, L., and Stead, D. E. 1992. Changing concepts in the taxonomy of plant pathogenic bacteria. Annu. Rev. Phytopathol. 30:67-105.

Zhao, B., Lin, X., Poland, J., Trick, H., Leach, J., and Hulbert, S. 2005. A maize resistance gene functions against bacterial streak disease in rice. Proc. Natl. Acad. Sci. U.S.A. 102:15383-15388.

Zhao, B. Y., Ardales, E., Brasset, E., Claflin, L. E., Leach, J. E., and Hulbert, S. H. 2004. The Rxo1/Rba1 locus of maize controls resistance reactions to pathogenic and non-host bacteria. Theor. Appl. Genet. 109:71-79. 